\section{Algumas reflexões sobre a preservação do patrimônio natural e cultural em áreas propensas às atividades minerárias}

\section{Jeanne Crespo}

Historiadora, doutoranda no Programa de Arquitetura e Urbanismo da Universidade Federal de Minas Gerais (UFMG) e técnica do Instituto do Patrimônio Histórico e Artístico Nacional IPHAN/MG, Rua Cardoso, 11 BI II apt 503, Santa Efigênia, CEP 30260-170, Belo Horizonte, MG, (31) 3481-4285, jeanne@iphan.gov.br

\section{Patrícia Urias}

Historiadora, mestranda no Programa de Arquitetura e Urbanismo da Universidade Federal de Minas Gerais (UFMG), Rua Barão do Rio Branco, 406, Centro, Caeté, CEP 34800-000, MG, (31) 3657-4869, patriciauriasbh@hotmail.com

\section{Resumo \\ O presente artigo procura discutir questões como a preservação dos Patrimônios Natural e Cultural em áreas de interesse para a exploração de mineradoras, utilizando-nos de estudos sobre os casos ocorridos no Estado de Minas Gerais, como a Serra da Piedade e a Serra do Gandarela, com base na leitura interpretativa crítica de normativas brasileiras e internacionais e de produção acadêmica sobre o tema.}

Palavras-chave: meio ambiente, patrimônio cultural, mineração.

s questões alusivas à preservação e a economia estão cada vez mais prementes em nosso cotidiano. Atualmente, uma das maiores preocupações tem girado em torno das questões de preservação do meio ambiente, sendo de fundamental importância pensar na diminuição de impactos sobre o mesmo, no momento da instituição de empreendimentos que impliquem em atividades exploratórias dos recursos ambientais.

A preocupação com a conciliação entre o crescimento econômico, a industrialização, o desenvolvimento tecnológico e os recursos ambientais do planeta, inicia a história do pensamento ambiental, iniciada com o movimento ambientalista surgido na Europa e nos Estados Unidos nos anos de 1960 e 1970, que, por sua vez, vinculou-se intrinsecamente ao conceito de desenvolvimento sustentável (OLIVEIRA, 2004, p.43).
Em 1972, o direito fundamental à preservação do meio ambiente e o direito à vida, em nível mundial, foram reconhecidos pela Declaração do Meio Ambiente, adotada na Conferência das Nações Unidas, em Estocolmo.

A referida Declaração consagrou que o ser humano tem direito fundamental à liberdade, à igualdade e a uma vida com condições adequadas de sobrevivência, num meio ambiente que permita usufruir de uma vida digna, com a finalidade também, de preservá-lo e melhorá-lo para as gerações atuais e futuras.

A partir de então, junto ao já assegurado direito dos povos ao desenvolvimento econômico, como forma de combater a miséria, preconizou-se as medidas de proteção da natureza. Desta forma, o desafio que se travou desde então foi o de encontrar 
meios de desenvolvimento econômico, industrial e tecnológico, com agressões mínimas ao meio ambiente, visando com isto, não violar também os direitos fundamentais da vida.

Assim, longe de procurarmos ser conclusivos sobre tal tema, que ainda será debatido por gerações, visto que é problema crucial para a continuidade da vida humana na terra, buscamos, no presente trabalho, discutir algumas questões relativas à exploração de recursos naturais com destinação ao aproveitamento econômico, mais propriamente, abordando a extração minerária em território mineiro e seus impactos.

Utilizaremo-nos para tanto, de dois casos ocorridos no Estado de Minas Gerais: a Serra da Piedade e a Serra do Gandarela. No primeiro caso, a unidade natural passou por um longo processo de atividade minerária, apesar de ter proteções oficiais de várias instâncias do poder público, e ainda hoje é alvo dessas atividades. Já no segundo caso, almeja-se instalar um projeto de empreendimento minerário orçado em 4 bilhões de reais, com meta extrativa de 24 milhões de toneladas de minério de ferro por ano.

\section{A legislação ambiental brasileira e a mineração}

De acordo com José Afonso da Silva, Meio Ambiente:

(...) é a interação do conjunto de elementos naturais, artificiais e culturais que propiciem o desenvolvimento da vida em todas as suas formas. A integração busca assumir uma concepção abrangente do ambiente, compreensiva dos recursos naturais e culturais. (SILVA, 1997, p.02)

Pânmia F. Vieira Ribeiro se aproxima da concepção de Silva em sua definição de meio ambiente, salientando, ainda, quão vital é um meio ambiente harmonicamente equilibrado para os seres humanos:

Constituem, pois, o meio ambiente, a coalizão de diferentes elementos, alguns de natureza natural, bem como aqueles considerados pelo seu valor histórico, artístico, turístico, paisagístico e arqueológico. Desta feita o meio ambiente é constituído por vários aspectos, que juntos propiciam a própria existência da sociedade humana. O solo onde se vive, o ar que se respira, as águas responsáveis pela essência de inúmeros ecossistemas, são tão indispensáveis, como os bens materiais ou imateriais, corpóreos ou incorpóreos sejam eles móveis de imóveis; que traduzem a historia de um povo, suas raízes étnicas, desenvolvimento biológico das espécies hoje existentes (RIBEIRO, 2011, p. 02).

As concepções de meio ambiente apresentadas corroboram a noção deste como integrante dos Direitos Humanos de Terceira Geração, que tratam mais especificamente dos direitos difusos, como a proteção ao patrimônio histórico e cultural. Desta forma, com a intenção de repreender os danos ambientais e assegurar uma vida digna para as gerações presentes e futuras, se formula o direito ambiental que, quando desrespeitado, significa uma violação a outros direitos fundamentais do homem, como a vida, a saúde e o bem estar.

Tal idéia encontra-se amparada pela Constituição Federal Brasileira de 1988, que classifica o meioambiente como um direito coletivo fundamental, prevendo no caput de seu artigo 225: Todos têm direito ao meio ambiente ecologicamente equilibrado bem de uso comum do povo essencial a sadia qualidade de vida impondo-se ao poder público e a coletividade o dever de defendê-lo e preservá-lo para as presentes e futuras gerações.

Segundo Magrini (2001), a evolução da política ambiental pode ser estruturada a partir de grandes acontecimentos internacionais ocorridos a partir da segunda metade do século $X X$, que influenciaram o curso das políticas ambientais no mundo e, consequentemente, no Brasil. Houve, nesse período, o desenvolvimento de três óticas em relação à questão ambiental: a ótica corretiva (preponderante nos anos 1970), a ótica preventiva (preponderante nos anos 1980) e finalmente, a ótica integradora (característica dos anos 1990), que fornece a base teórica para a elaboração das ações políticas ambientais atuais.

Tal ótica integradora pode ser percebida em vários instrumentos que dispõem sobre o meio ambiente, como a Lei 6.938/81, as Resoluções do Conselho Nacional de Meio Ambiente - CONAMA n 001/86 e n 237/97, a Constituição Brasileira de 1988 e o Parecer n 312 de 2009 do Ministério do Meio 
Ambiente. Tais dispositivos, além de normatizarem a Política Nacional do Meio Ambiente, instituíram o licenciamento ambiental como uma obrigação legal prévia à instalação de qualquer empreendimento ou atividade potencialmente poluidora ou degradadora do meio ambiente, atribuindo tal competência a uma gestão partilhada entre as instituições municipais, estaduais e a federal de Meio Ambiente, como partes integrantes do Sistema Nacional de Meio Ambiente - SISNAMA.

Como parte do processo de licenciamento, se exige a elaboração do Estudo de Impacto Ambiental - EIA e o respectivo Relatório de Impacto Ambiental RIMA sendo dada, obrigatoriamente, publicidade ao processo. A composição do EIA apresenta diagnóstico ambiental da área de influência do empreendimento, com completa descrição e análise dos recursos ambientais e suas interações, tais como existem, de modo a caracterizar a situação ambiental da área, antes da implantação do mesmo, considerando, além do meio ambiente físico e natural, o meio ambiente socioeconômico.

Os estudos de diagnóstico ambiental relativos ao meio ambiente socioeconômico, tais como previstos pela Resolução no. 001 do Conselho Nacional do Meio Ambiente - CONAMA de 1986 devem levar em consideração os sítios e monumentos arqueológicos, históricos e culturais das comunidades locais, as relações de dependência entre a sociedade local, os recursos ambientais e a potencial utilização futura desses recursos. Com isso, verifica-se mais uma vez a concepção ambiental da legislação brasileira, que inclui a preservação dos bens de interesse cultural no conceito de um meio ambiente equilibrado.

Como a preservação dos recursos naturais e culturais frente às necessidades da implantação de empreendimentos e/ou atividades potencialmente impactantes aos mesmos passa necessariamente, pelo licenciamento ambiental, podemos entender que os estudos ambientais prévios à implantação de um empreendimento constituem-se em uma forma de compreender a politização do espaço social a partir da apreensão das suas formas de produção, apropriação e organização (BONIZATTO, 2004, p. 171).

Esta politização do espaço é corroborada pelo princípio da legislação brasileira que atribui tanto ao poder público quanto à coletividade o dever de defender o meio ambiente, a partir de normas que garantam a informação ambiental como direito publico subjetivo e a participação das entidades, associações e indivíduos nos processos de tomada de decisão, por meio de audiências públicas, por exemplo. Tal interação entre Estado e sociedade pode ser entendida sob o prisma da gestão ambiental.

De acordo com Braga (2002, p. 222), a gestão do ambiente é entendida como a forma sistemática da sociedade encaminhar a solução de conflitos de interesse no acesso e uso do ambiente pela humanidade. O autor Phillipi Jr. (2004, p. 03) diz que o processo de gestão ambiental inicia-se quando se promovem adaptações ou modificações no ambiente natural, de forma a adequá-lo às necessidades individuais ou coletivas. Ainda, de acordo com o autor citado, a maneira de gerir a utilização dos recursos naturais é o fator que pode acentuar ou minimizar os impactos ambientais. 0 termo gestão ambiental compreende um conjunto de procedimentos que visam à conciliação entre o desenvolvimento e a qualidade ambiental, a partir de um planejamento ambiental.

Segundo Santos (2004, pp. 27-35) o planejamento ambiental surgiu nas três últimas décadas, em razão do aumento dramático da competição por terras, água, recursos energéticos e biológicos, que determinaram a necessidade de organizar o uso da terra, de compatibilizar esse uso com a proteção de ambientes ameaçados, bem como melhorar a qualidade de vida das populações. O mesmo autor afirma que este pode se apresentar sob diferentes formas. Para o caso brasileiro, o mesmo aponta exemplos como Zoneamentos, Planos de Bacias Hidrográficas, Planos de Manejo, Planos Diretores e Estudos de Impacto Ambiental.

Para o caso de impactos ambientais resultantes de atividades de mineração, o planejamento ambiental previsto pela legislação brasileira se embasa no preconizado pelas resoluções CONAMA 001/1986 e 237/1997, que tratam da exigência dos EIA's e demais instrumentos de comando e de controle como RIMA's, Planos de Controle Ambientais PCA's, Relatórios de Controle Ambientais - RCA's, planos de monitoramentos e planos de fechamento de mina. E apesar de cada Estado componente da federação brasileira, assim como alguns municípios 
Figura 1: Vista da Igreja de Nossa Senhora da Piedade. Foto: Jeanne Crespo, 2011 também possuírem órgãos de meio ambiente com legislações próprias, estas não podem contrariar princípios básicos vislumbrados pela legislação federal e pelas resoluções do CONAMA.

Ainda, há a exigência da apresentação dos estudos acima referenciados em audiências públicas, a aprovação dos mesmos pelos conselhos estaduais e municipais de meio ambiente, entre outros. Após o exposto, verificaremos a seguir como tais instrumentos legislativos de gestão e planejamento ambiental atuaram em dois casos ocorridos no Estado de Minas Gerais.

\section{A Serra da Piedade}

Localizada no Quadrilátero Ferrífero, no centro leste de Minas Gerais, em uma área que se encontra dentro dos limites das cidades de Caeté e Sabará, a Serra da Piedade se constitui em um sítio de interesse natural, cultural e paisagístico, com grande relevância religiosa e turística.

Em 1956, o Instituto do Patrimônio Histórico e Artístico Nacional - IPHAN efetuou o tombamento do "Conjunto Arquitetônico e Paisagístico do Santuário de Nossa Senhora da Piedade" através do Processo de n526-T-55, inscrevendo-o nos livros de Tombo
Histórico e de Tombo Arqueológico, Etnográfico e Paisagístico.

A Serra da Piedade também é patrimônio cultural de Minas Gerais, objeto de proteção pela Constituição Estadual de 1989, conforme disposto no Artigo no. 208 e no Artigo no. 84 do "Ato das Disposições Transitórias Constitucionais", que efetuou o seu tombamento e a declarou Monumento Natural, ao lado das serras do Caraça, do Ibitipoca, do Cabral e dos Picos do Itabira, do Ibituruna e do Itambé.

Em 2001, o município de Caeté, através do Art. no. 202 de sua Lei Orgânica Municipal efetuou o tombamento do "Conjunto Cultural, Arquitetônico, Paisagístico e Natural da Serra da Piedade" a partir da cota de 1200 metros até o cume, dentro dos limites do município. Em 2003, criou-se também a APA Águas Serra da Piedade, através da Lei $n^{\circ}$ 2.335, com o objetivo de proteger seus mananciais de água

Em 2004 foi sancionada a Lei Estadual n 15.178, que definiu os limites da área de conservação da Serra da Piedade, em cumprimento ao disposto no parágrafo $1^{\circ}$ do Artigo no. 84 do Ato das Disposições Constitucionais Transitórias da Constituição do Estado de Minas Gerais.

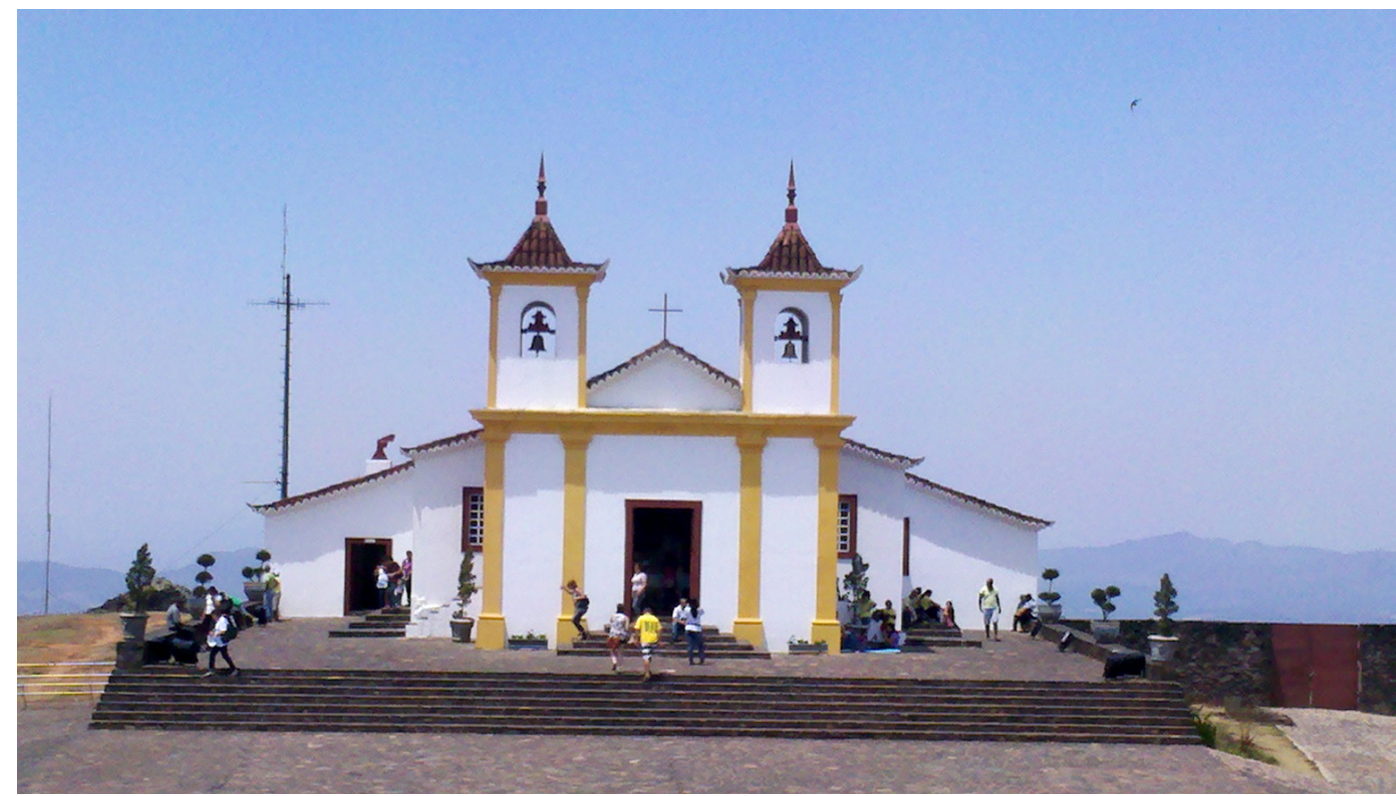




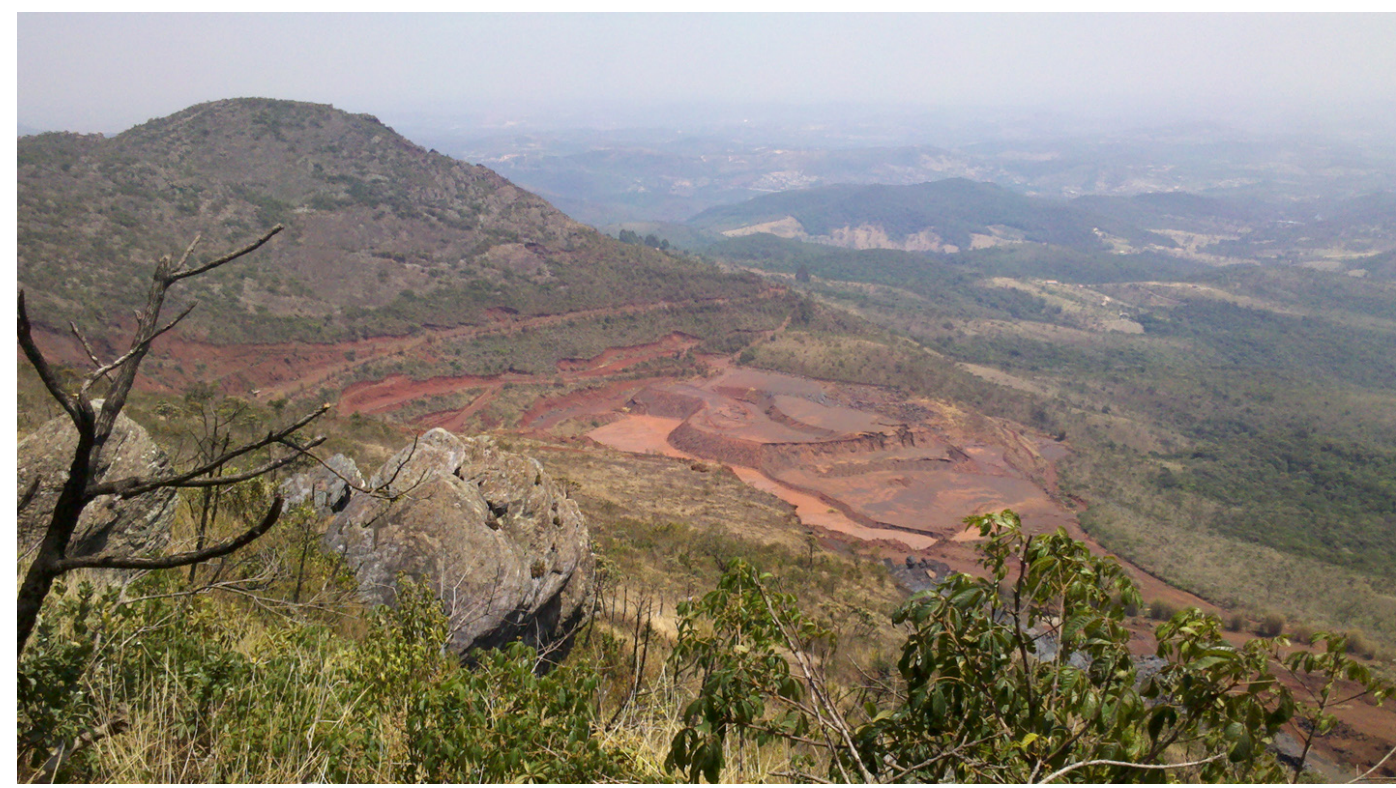

Figura 2: Vista da alteração na paisagem causada pelo empreendimento minerário na Mina do Brumado, assim como visto da estrada que leva ao Santuário de Nossa Senhora da Piedade. Foto: Jeanne Crespo, 2011.
Em 2005, o Conselho Curador do Instituto Estadual do Patrimônio Histórico e Artístico de Minas Gerais (IEPHA) deliberou e aprovou o parecer técnico daquele Instituto que concluiu que a delimitação estabelecida pela Lei $n^{\circ}$ 15.178/04 poderia ser considerada como o perímetro do tombamento estadual do conjunto paisagístico e arquitetônico da Serra da Piedade.

Neste mesmo ano, a Organização das Nações Unidas para Educação, Ciência e Cultura - UNESCO entregou oficialmente o título de "Reserva da Biosfera" ao trecho mineiro do maciço da Serra do Espinhaço, do qual faz parte a Serra da Piedade.

Em 2006 foi promulgada a Lei Estadual no. 16.133, que dentre outros assuntos, tratou da alteração do perímetro de tombamento estadual original da serra, diminuindo-o. A aprovação desta lei foi motivo de Ação Civil Pública por parte do Ministério Público Estadual e do Federal, com relação à legalidade, motivação e instrução de tal ato administrativo.

Apesar de ser protegida oficialmente pelo IPHAN e pelo IEPHA, em 1997 foram concedidas à Brumafer Mineração Ltda. licenças de operação para dois processos com decretos de lavra, emitidos em 1976 e 1977 pelo Departamento Nacional de Produção
Mineral - DNPM, para local denominado Mina do Brumado, localizado no entorno imediato do tombamento federal. Assim sendo, desde 1997 até 2006 a referida empresa explorou os recursos minerais do local, danificando a paisagem do entorno do bem protegido.

Em novembro de 2005, o IPHAN, o Ministério Público Estadual de Minas Gerais e o Ministério Público Federal moveram uma ação civil pública pela degradação causada à Serra da Piedade, com pedido de liminar para a imediata cessação da exploração minerária no local e para que não fosse praticado qualquer ato administrativo tendente à renovação de licenças e à concessão de licenças prévias na área protegida .Em dezembro, a Justiça Federal deferiu a referida liminar e, a partir de meados de janeiro de 2006, as atividades na área foram paralisadas.

A degradação paisagística da Serra da Piedade chama atenção às deficiências da legislação brasileira que regula a exploração minerária, principalmente, no momento que posterga a recuperação ambiental das áreas degradadas para o final da exploração das lavras, quando os lucros da exploração já foram auferidos, aliadas às dificuldades para a fiscalização ambiental em um país com as dimensões do Brasil. 


\section{A Serra do Gandarela}

A Serra do Gandarela localiza-se na Serra do Espinhaço, mais especificamente no Quadrilátero Ferrífero, abrangendo partes dos municípios de Caeté, Raposos, Rio Acima, Barão de Cocais, Itabirito e Santa Bárbara.

Apesar de estar próxima à Região Metropolitana de Belo Horizonte, a área apresenta baixa ocupação humana, havendo extensos e diversos ambientes naturais preservados e apresentando feições de relevo de grande beleza, notáveis também sob o ponto de vista geomorfológico.

Sua extensão é de aproximadamente 38 mil hectares, formando um corredor ecológico com a Reserva Particular de Patrimônio Natural Santuário do Caraça e a Floresta Estadual Uaimii, contribuindo para que as mesmas não fiquem "ilhadas".

Existem na região mais de 1.000 nascentes que

Figura 3: Vista da Serra do Gandarela do Vale do Córrego do Maquiné. Foto: Patrícia Urias, 2009. alimentam, com águas Classe Especial e Classe 1, a Região Metropolitana de Belo Horizonte e as bacias dos rios São Francisco e Doce.
A região é o último fragmento significativo de áreas naturais em bom estado de conservação dentro do Quadrilátero Ferrífero, como relevância máxima para conservação: alta vulnerabilidade ambiental, alta integridade da flora e alta vulnerabilidade à erosão.

Possui uma rica Biodiversidade com variedade de ambientes (mata atlântica, campo rupestre e cerrado), diretamente relacionada à riqueza de espécies existentes e à grande diversidade biológica, com taxas excepcionais de ocorrência de espécies raras, endêmicas (encontradas apenas naquele tipo de ambiente) e ameaçadas de extinção.

A Serra do Gandarela não possui proteções oficiais em níveis estadual e federal, como a Serra da Piedade. No entanto, possui proteções em nível municipal, como o Tombamento realizado pelo município de Raposos, que aponta para o importante elo histórico desta Serra na formação do município, que surgiu na confluência da foz do ribeirão da Prata com o rio das Velhas. Neste local, a população manteve ligação histórica, como lugar de lazer e de atratividade turística. Existe a presença de diversas cachoeiras, poços e praias com formações de grande beleza

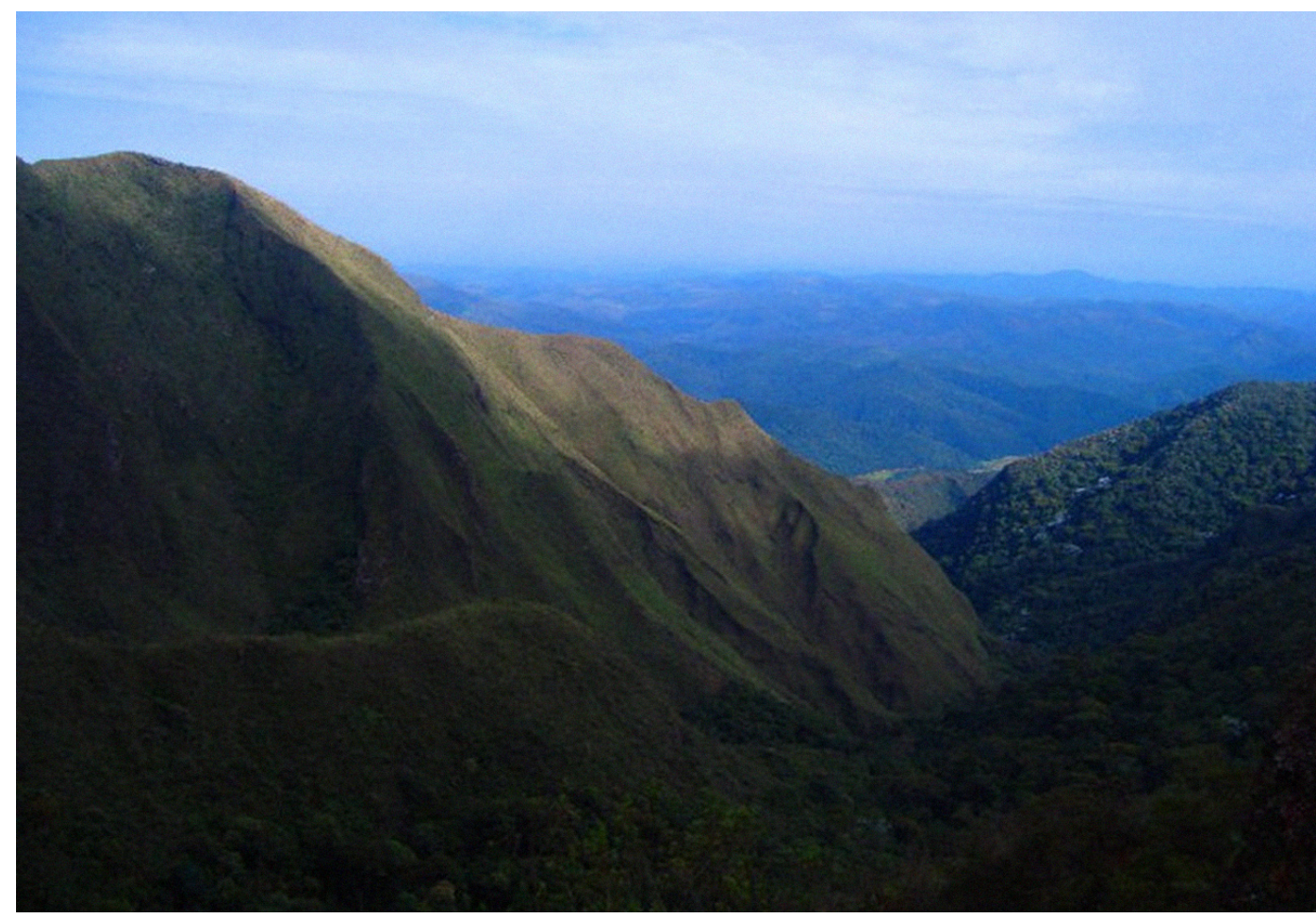


cênica e a presença de ruínas e construções históricas do ciclo do ouro.

Parte da Serra do Gandarela também é protegida por tombamento municipal do município de Santa Bárbara do Conjunto Natural, Paisagístico e Paleontológico da Bacia do Gandarela. Esta possui fósseis vegetais de três períodos distintos e cistos de dinoflagelados continentais, entre 10 e 40 milhões de anos, sendo candidata aprovada pela Comissão Brasileira dos Sítios Geológicos e Paleobiológicos SIGEP a Patrimônio da Humanidade pela Organização das Nações Unidas - ONU.

Mesmo possuindo estes instrumentos de proteção e tendo reconhecido valor biótico, histórico e paleontológico, com grande potencial turístico e científico, a Serra do Gandarela, tal qual a Serra da Piedade, também é alvo de empresas interessadas na exploração minerária do local. Atualmente, a Vale S.A. pretende implantar a Mina Apolo na região. Um projeto orçado em 4 bilhões de reais, objetivando com a atividade extrair 24 milhões de toneladas de minério de ferro por ano.

Em 2009, foi apresentada ao Instituto Chico Mendes de Conservação da Biodiversidade - ICMBio pelo Projeto Manuelzão/ UFMG, a proposta de criação de um Parque Nacional na região do Gandarela, tendo como base os estudos apresentados em uma dissertação de mestrado do Instituto de Geociências da UFMG. Após as análises iniciais, confirmou-se a pertinência de tal pleito, passando-se então aos estudos técnicos e à consolidação da proposta de criação de Unidade de Conservação Federal, conforme a Instrução Normativa no. 005 de 2008 do ICMBio.

Com o início dos estudos, os Ministérios Públicos Estadual de Minas Gerais e Federal moveram ações contra quaisquer processos de licenciamento ambiental na região, até que se resolva a situação da criação ou não da Unidade de Conservação.

\section{Algumas questões referentes à relação mineração x preservação ambiental}

Os municípios de Minas Gerais que possuem empreendimentos minerários apresentam marcas evidentes em suas paisagens e áreas ambientalmente comprometidas, uma vez que, de maneira geral, os efeitos da mineração, desde a lavra até o tratamento do minério:

São efeitos visíveis, detectados a curto prazo, denominados de agudos e afetam: a paisagem (desaparecimento de morros; aterros de depressóes; transformações, inclusive por assoreamento de drenagem); o solo (remoção, decapagem e aterro); a vegetação (desflorestamento). Sobre a qualidade do meio. Efeitos não-visíveis, detectados a longo prazo. Esses efeitos são considerados crônicos e sentidos principalmente por: modificação na qualidade da água (efeito na qualidade de recursos hídricos); absorção ou assimilação (cutânea, respiratória ou digestiva) por animais: podem afetar organismos superiores (inclusive o homem), modificações da qualidade do ar (emissão de particulados), modificação do meio físico, inclusive trazendo efeitos a curto, médio e longo prazos sobre o clima local. (BRUM, 2000, p. 02)

Além das implicações ambientais decorrentes da supressão de vegetação, erosão do solo, comprometimento dos lençóis freáticos, alteração na paisagem e no meio biótico, dentre outras, a exploração minerária também acarreta intervenções no meio social das comunidades que vivem próximas a tais empreendimentos.

De acordo com Amélia Enríquez (2007, p. 20), a atividade minerária de larga escala é recente no Brasil. Assim, esta autora verificou a associação entre a idade da mina, o seu potencial de impacto ambiental e a localização geográfica. As minas mais antigas teriam mais passivos ambientais, enquanto as mais jovens, quando implantadas obedecendo todos os trâmites da legislação vigente, incorporariam melhor os princípios de gestão ambiental, gerando menos passivos ambientais graves.

De acordo com a mesma autora, a tendência da atividade minerária no Brasil é se expandir para a região Norte, cujo território está ainda pouco explorado e porque muitas das minas das regiões Sudeste e Sul já estão em fase de esgotamento. No entanto, os crescentes preços que commodities minerais vem alcançando nos últimos anos, tem permitido o aumento da vida útil da mineração nestas regiões 
1 Extrafiscalidade: é a característica que tem o tributo de não só gerar receitas para o Estado, mas de estimular ou desestimular o comportamento dos agentes econômicos, influindo nas decisões particulares.

2 A NOSA Certification Authority (NCA) abrange um leque amplo de serviços que vão desde auditorias de conformidade legal básica até auditorias dos sistemas de gestão de segurança, saúde e meio ambiente.
João Carlos Bezerra da Silva (2010) elenca alguns instrumentos com o intuito de conciliar a preservação do meio ambiente com a atividade extrativista. $\mathrm{O}$ primeiro instrumento conciliador no conflito entre desenvolvimento econômico e equilíbrio ambiental é o sistema tributário, que ocupa uma posição fundamental como integrante do ordenamento jurídico constitucional. Mais do que mero instrumento arrecadador de receitas para o Estado, a tributação exerce um grande papel de instrumento interventor no sistema de preços de mercado e de indutor de comportamentos.

Conforme Bezerra da Silva (2010), tal característica é proporcionada pela denominada extrafiscalidade? aspecto da tributação muito mais estudada pela teoria econômica do que pelo Direito, pois é utilizada como instrumento de estímulo da demanda agregada. Assim, ao atuar no mecanismo de mercado, o sistema tributário pode modificar os preços das mercadorias, alterando o comportamento dos agentes econômicos e direcionando-os para opções ecologicamente mais desejáveis.

De acordo com Maria Enríquez (2009, p. 2-3), há mecanismos indutores de mercado que exercem forte pressão para uma atitude ambientalmente mais proativa por parte da indústria minerária, tais como as negociações de ações das companhias mineradoras em bolsas de valores, além de instrumentos como a adesão aos programas internacionais de certificação ambiental da série ISO 14.000 e NOSA², por exemplo. Desta forma, o destino das vendas dos minérios (mercado exterior europeu, norte-americano, chinês, ou mesmo mercado interno) também contaria para uma gestão ambiental mais eficaz em um empreendimento minerário, uma vez que, quanto mais exigente for o comprador em termos de certificados ambientais, mais cauteloso será o empreendimento.

Um segundo instrumento citado por Silva (2010, p.15) é o Zoneamento Ecológico Econômico - ZEE, fundamental para o gerenciamento territorial da atividade econômica, compatibilizando preservação do meio ambiente e o desenvolvimento econômico, sendo possível, através do mesmo, chegar a uma alocação territorial compatível com a exploração racional dos recursos naturais.

Para este autor, ainda, ressalta o caráter democrático e conciliador de conflitos entre os interesses de tal instrumento, na medida em que no mesmo pode estar previsto que a população diretamente afetada por empreendimentos econômicos específicos possui legitimidade para decidir qual a melhor distribuição geográfica das atividades econômicas.

O Estudo de Impacto Ambiental - EIA e o licenciamento ambiental são outros instrumentos importantes para se administrar a relação economia-ecologia.

O licenciamento ambiental que tem por finalidade a limitação à construção, instalação, ampliação e funcionamento de estabelecimentos e atividades que utilizem recursos ambientais, considerados efetiva e potencialmente poluidores, bem como os capazes, sob qualquer forma, de causar degradação ambiental, na acepção da própria Política Nacional do Meio Ambiente (SILVA, 2010, p.30). O instrumento do licenciamento ambiental é um ato administrativo de natureza política, que busca levar em consideração aspectos técnicos e jurídicos para a concessão das licenças. Quando realizado de forma adequada, se mostra uma ótima oportunidade de vislumbre do papel do Estado como conciliador entre os interesses econômicos das empresas e o interesse social.

O licenciamento ambiental deve ser divulgado publicamente, de forma a promover a participação da sociedade civil nas instâncias de decisão. Vemos a participação de setores da sociedade nos Conselhos de Meio Ambiente e nas Audiências Públicas, por exemplo. No entanto, o que devemos nos questionar é sobre a qualidade de tal representação. Nos casos por nós abordados, a participação das comunidades a serem impactadas com os empreendimentos não se deu de forma constante durante os respectivos processos de licenciamento ambiental e não se configurou na participação destes grupos como sujeitos do processo de gestão ambiental. Inclusive, as comunidades tiveram que utilizar a intervenção do Ministério Público para terem suas requisições legitimadas.

Já o EIA, considerado um estudo científico multidisciplinar, é capaz de visualizar tanto as inúmeras consequências dos empreendimentos econômicos, abrangendo não só os aspectos econômicos e ambientais, mas também as consequências sociais. Este é um importante instrumento auxiliar na tomada de decisões necessárias à implantação dos 
empreendimentos e/ou atividades econômicas, notadamente no que diz respeito às ações mitigadoras das consequências ambientais e sociais negativas. No entanto, o que acontece no Brasil é que cada vez mais tal instrumento tem cumprido um papel burocrático pro forme, ao invés de sua função de diagnosticar a viabilidade ou não de um determinado empreendimento.

Desta forma, ao invés da prevenção vence a ótica da compensação. No entanto, os danos ambientais, assim como seus impactos sociais muitas vezes não deveriam ser mesurados apenas em valores passíveis de reparação financeira.

Como uma das condicionantes primordiais solicitadas durante o processo de licenciamento ambiental de um empreendimento minerário, a previsão de recuperação das áreas mineradas e seu monitoramento aparecem como ferramenta importante para a minimização dos impactos citados.

Conforme Brum (2000, p. 02) a recuperação de determinada área degradada por um empreendimento minerário pode ser definida como o conjunto de ações necessárias para que a mesma volte a estar apta para algum uso produtivo em condições de equilíbrio ambiental.

Assim, na opinião deste autor, tal planejamento de recuperação de uma área degradada pela mineração poderia ser resumido na execução dos seguintes procedimentos básicos: compromisso do empreendedor com os trabalhos de recuperação, avaliação detalhada da área degradada (envolvendo a identificação dos processos de degradação, identificação dos impactos ambientais existentes e definição dos indicadores ambientais), definição dos objetivos da recuperação (compreendendo o estabelecimento de resultados e metas a serem alcançados a curto e médio prazo, elaboração de um plano ou projeto de recuperação, compreendendo métodos e técnicas a serem empregados, cronograma, previsão dos recursos humanos, materiais e financeiros que serão utilizados).

H. Mota de Lima (2006) discorre acerca do instrumento chamado Plano de Recuperação de Áreas Degradadas ou Alteradas (PRAD), dizendo que a obrigação fundamental imposta aos titulares de concessões de lavras no Brasil, com relação ao fechamento de minas, é que eles promovam a reabilitação das áreas impactadas pelas atividades da mineração, de acordo com o PRAD, previamente elaborado e aprovado pelo órgão governamental competente.

As medidas de recuperação executadas requerem vistorias e inspeções periódicas, visando manter as condições necessárias ao cumprimento dos objetivos preestabelecidos no plano de recuperação. De acordo com Bitar:

A eficácia das medidas adotadas deve ser acompanhada por meio de indicadores ambientais que, nesta atividade, podem ser denominados como indicadores de desempenho, visando verificar se os parâmetros estão sendo ajustados e se a recuperação está sendo bem sucedida. Eventuais resultados satisfatórios podem exigir desde a reavaliação da área degradada e a reformulação das medidas executadas até, se necessário, sua complementação ou substituição. (BITAR, 1997, p. 54)

Assim, um plano de fechamento de Minas consistente deve levar em consideração questões como:

a) A garantia da segurança e da saúde pública, através da reabilitação das áreas perturbadas pela mineração, de modo a retorná-las às condições desejáveis e necessárias à implantação de um uso pós-mineração previamente eleito e socialmente aceitável;

b) A identificação dos agentes envolvidos por ocasião da implantação da mina, das partes interessadas e de consulta à comunidade;

c) Abordagem do processo de recuperação das áreas afetadas a partir da análise de riscos. A abordagem de tal análise aponta para os riscos potenciais no fechamento e pós-fechamento de uma mina, através de um processo de identificação das fontes potenciais, avaliação dos riscos e planejamento das ações mitigadoras adequadas;

d) A estimativa dos custos de reabilitação das áreas, com cronograma contendo estimativa física e de custos, apresentando, assim, garantias para o propósito específico do fechamento, que é assegurar aos agentes e partes envolvidas que os custos 
de implantação e gerenciamento do plano de fechamento estão adequadamente contemplados no planejamento financeiro da empresa de mineração e não serão transferidos aos órgãos governamentais ou à comunidade, por ocasião da exaustão das reservas minerais da mina, ou em caso de ocorrer interrupção abrupta da produção, como consequência, por exemplo, da falência da empresa de mineração;

e) Critérios de fechamento e abandono da área, onde os responsáveis pelo empreendimento comprovem que foram cumpridas todas as metas, sejam elas legais, sociais, ambientais e técnicas, acordadas com as instituições competentes, assim como com as comunidades envolvidas, levando em consideração quesitos previamente enumerados e adotados para essa avaliação.

Bitar (1997), ainda, elenca três medidas para recuperação das áreas degradadas pelas atividades minerárias: a revegetação, as medidas geotécnicas ou geotecnológicas, e a remediação.

O método de revegetação envolve desde a fixação localizada de espécies vegetais (herbáceas, arbustivas e arbóreas) até a implantação de reflorestamentos extensivos, tanto para fins de preservação ou conservação ambiental quanto para objetivos econômicos, incluindo a geração de condições propícias ao repovoamento da fauna e à regeneração de ecossistemas primitivos ou originais.

Já, as geotécnicas, ou geotecnologias visam à estabilização física do meio ambiente, geralmente, compreendendo procedimentos técnicos da mecânica dos solos, mecânica das rochas, geologia e engenharia.

A remediação, por sua vez, é o método que envolve o uso de técnicas de tratamento que visam a eliminar, neutralizar, imobilizar, confinar ou transformar elementos ou substancias contaminantes presentes no ambiente.

3 Lixiviado: Material removido por lixiviação. Lixiviação: é o processo de extração de uma substância presente em componentes sólidos através da sua dissolução num líquido. Termo utilizado em vários campos da ciência, tal como a geologia, ciências de solo, metalurgia e química.
No caso de solos e águas subterrâneas contaminadas, os métodos geralmente envolvem técnicas de tratamento in situ. No caso de águas superficiais, sedimentos, lodos ou lixiviados ${ }^{3}$, especialmente quando visa restabelecer padrões de qualidade ambiental, caracterizam-se como técnicas de saneamento. Comumente, as técnicas de remediação compreendem processos químicos, mas, dependendo do caso, podem envolver também processos físicos e biológicos.

Bitar (1997) também indica possibilidades de usos póstumos diferenciados para áreas afetadas pela mineração, tais como: habitação, agricultura, pastagens, comércio, indústria, disposição de resíduos, reflorestamento, lazer, recreação, esportes, preservação, conservação ambiental, piscicultura, entre outras formas de uso e ocupação. Estas são algumas alternativas de recuperação ou reabilitação para áreas de diferentes bens minerais em países industrializados como EUA, Canadá, França, Alemanha, dentre outros.

No Brasil, há normativas que estabelecem exigências mínimas e norteiam a elaboração de Projetos de Recuperação de Áreas Degradadas, como a NBR 13030 de 1999 e a recente Instrução Normativa n 4 de 13 de Abril de 2011 do Instituto Brasileiro de Meio Ambiente e Recursos Renováveis - Ibama. No entanto, como as instituições que tem como competência o licenciamento ambiental e a fiscalização de tais empreendimentos são muitas, e todas com suas legislações próprias, mesmo com a prerrogativa de acordo com a legislação federal e resoluções CONAMA, fica complexo o estabelecimento de critérios mínimos passíveis de serem aplicados ao território nacional como um todo, para avaliação dos trabalhos implantados e para mensuração da responsabilidade dos empreendedores em relação aos passivos que afetam os meios natural e social.

Assim, chegamos a um dos instrumentos conciliadores mais importantes: as políticas públicas. É importante observar que apesar de haver uma legislação em vigor, a implantação de políticas direcionadas ao atendimento dos interesses sociais é também uma decisão que, apesar de estar vinculada a critérios técnicos, depende da vontade política dos dirigentes e agentes públicos.

João Carlos Bezerra da Silva (2010) chama a atenção para o fato de que é fundamental percebermos que os instrumentos conciliadores abordados não garantem sozinhos a efetividade do equilíbrio entre economia e proteção ambiental. Por isto, é preciso que os instrumentos existentes, juntamente com outros que vierem a existir, estejam trabalhando conjuntamente e harmonicamente, como forma de garantir a máxima efetividade dos direitos fundamentais constitucionalmente garantidos. 


\section{Conclusão}

Podemos perceber, sem muita dificuldade, que a necessidade de preservação está cada vez mais presente em nossas vidas. As diversas atividades industriais precisam estar voltadas para essa questão fundamental, pois a vida do homem e todas as formas de vida na terra dependem dessa atitude consciente.

A legislação brasileira busca atender à conciliação entre crescimento econômico e bem estar social, no intuito de promover o desenvolvimento econômico, no sentido mais amplo do termo. No entanto, o caráter interpretativo dos dispositivos legais, assim como sua transitoriedade, facilitam "brechas" interpretativas da legislação ambiental. Ainda, contamos com a pouca integração entre as esferas federal, estaduais e municipais. Junte-se a isto a deficiente interação entre instituições envolvidas no processo, principalmente quando há a necessidade de interlocução entre instituições ambientais e aquelas que lidam com outros interesses sociais como patrimônio cultural, populações indígenas, quilombolas e rurais.

Os estudos de viabilidade ambiental e planos de recuperação devem ser avaliados de uma maneira mais crítica pelas instituições ambientais, não como "liberadores" do empreendimento, mas sim como instrumento de real diagnóstico e prognóstico das áreas a serem afetadas.

Deveria haver um planejamento racional para utilização dos recursos naturais a serem explorados com finalidade industrial no território brasileiro, de forma a proporcionar pelas instituições ambientais uma real análise das características sinérgicas causadas pela implantação de empreendimentos passíveis de impactos ambientais.

Os problemas ecológicos provocados pela atividade mineradora dependem do tipo de minério extraído, das características físicas da mineralização, da tecnologia existente, do destino da venda dos minérios (mercado externo ou doméstico), da data em que se iniciou a sua exploração e da região geográfica. Nesse sentido, não é possível pensar em um modelo único de gestão ambiental para a mineração, tendo em conta as profundas assimetrias entre os municípios brasileiros. Ela precisa ser contextualizada, a partir de uma base de conhecimento da realidade na qual a atividade ocorrerá.

Como regra geral, a mineração de larga escala destina sua produção ao mercado exportador. A crescente concorrência e as exigências de alguns compradores desse mercado requerem padrões ambientais rigorosos. Existem companhias mineradoras que adotam padrões legais de normas vigentes. Portanto, estar em conformidade com a legislação local não significa que ocorra uma excelente prática ambiental, podendo a destinação externa funcionar como um verdadeiro freio às práticas ambientais predatórias.

Com a diversificação dos mercados globais e o intenso crescimento de economias, como a da China, por exemplo, que não apresentam padrões ambientais rigorosos, é necessário estar alerta para possíveis retrocessos na qualidade ambiental das empresas extrativistas de minério, uma vez que os novos grandes mercados consumidores podem ocasionar a expansão das mineradoras para regiões ricas em recursos naturais e ambientais, mas que carecem de uma legislação efetiva de proteção ao meio ambiente.

Nos casos abordados neste artigo, podemos notar que o princípio da participação popular preconizado pelo texto constitucional, ao invés de funcionar como um entendimento entre os interessados no processo, no sentido de promoção de uma gestão ambiental participativa, cidadã e consciente, configurou-se em uma relação conflituosa entre sociedade civil, empresários e instituições governamentais. Em ambos os casos, coube ao Ministério Público o papel de fiscal do bem estar social, constituindo-se o próprio Poder Executivo como réu.

\section{Referências bibliográficas}

BASTOS, A.C.S.; ALMEIDA, J.R. "Licenciamento ambiental brasileiro no contexto da avaliação de impactos ambientais". In: CUNHA, G (org.). Avaliação e perícia ambiental. Rio de Janeiro: Bertrand Brasil, 2006.

BONIZZATO, Luigi. O advento do Estatuto da Cidade e consequências fáticas em âmbito da propriedade, vizinhança e sociedade participativa. Rio de Janeiro: Lúmen JÚRIS, 2004.

BITAR, O. Y. Avaliação da recuperação de áreas degradadas para mineração Região Metropolitana de São Paulo. Tese de Doutorado. São Paulo: USP, 1997. 
BRAGA, Benedito et al. Introdução à engenharia ambiental. São Paulo: Prentice Hall, 2002.

BREDARIOL, C. Conflito ambiental e negociação para uma política local de meio ambiente. Tese de doutorado. Rio de Janeiro: UFRJ; COPPE, 2001

BRUM, I. A. S. de. Recuperação de áreas degradadas pela mineração. Monografia. Escola Politécnica: UFBA, 2000.

CORUJO, M. T. V. F. et al. Serra da Piedade: berço da padroeira de Minas Gerais, Brasil. Patrimônio histórico, religioso, geológico e ambiental. Beleza, religiosidade, proteção e ameaças. Dossiê. Belo Horizonte, 42 p. Março, 1990.

ENRIQUEZ, M.A.R.. "Mineração e desenvolvimento sustentável É possível conciliar?". Revista Iberoamericana de Economía Ecológica. Vol. 12, p. 51-66, 2009. wuw.raco. cat/index.php/Revibec/article/viewFile/164733/216709. Acessado em 27 de junho de 2011

FACIN, Andréia Minussi. "Meio ambiente e direitos humanos". Jus Navigandi, Teresina, ano 7, n. 60, nov. 2002. Disponível em: <http://jus.uol.com.br/revista/ texto/3463>. Acessado em: 02 maio de 2011.

FARIAS, C.E.G. Mineração e Meio Ambiente. http:// www.em.ufop.br/ceamb/petamb/cariboost_files/ miner_c3_a7_c3_a3o_20e_20meio_20ambiente. pdf. Acessado em 10/05/2011

OLIVEIRA, F. P. M.: GUIMARÃES, F. R. Direito, meio ambiente e cidadania: uma abordagem interdisciplinar. São Paulo: Madras, 2004

PHILIPPI Jr., A.; ROMÉRO, M. A.; BRUNA, Gilda Collet. "Uma introdução à questão ambiental". In: Curso de Gestão Ambiental. Barueri, SP: Manole, 2004. V.1, p.3-16.
LIMA, H. M et al. "Plano de recuperação de áreas degradadas versus plano de fechamento de mina: um estudo comparativo." REM: Revista da Escola de Minas, Ouro Preto, ano 59, n.4, p.397-402, out. dez. 2006

MAGRINI, A. Gestão Ambiental. PPE/ COPPE/ UFRJ 2001.

RIBEIRO, P.F.V. "Tombamento: Instrumento de Proteção Ambiental". Revista Direito \& Dialogicidade, América do Norte, 117052010

SACHS, I. "As cinco dimensões do ecodesenvolvimento". In: SACHS,I. Estratégias de transição para o século XXI: desenvolvimento e meio ambiente. São Paulo: Studio Nobel, 1993.

SANDRONI, Paulo. Dicionário de economia. São Paulo: Atlas, 1994.

SANTOS, R.F. Planejamento ambiental: teoria e prática. São Paulo: Oficina de Textos, 2004

SILVA, J.C.B.. "Os instrumentos jurídico-econômicos conciliadores do conflito entre o desenvolvimento econômico e o meio ambiente ecologicamente equilibrado. Jus Navigandi, Teresina, ano 15, n 2419, 14 fev. 2010. http://jus.uol.com.br/revista/ texto/14347. Acessado em: 2 maio de 2011

SILVA, J.A. Direito Ambiental Constitucional. São Paulo: Malheiros, 1997.

SILVA, J.A . Curso de Direito Constitucional Positivo. São Paulo: Malheiros, 2003.

SOUZA, N.J. Desenvolvimento econômico. São Paulo: Atlas, 1993. 